\title{
A descriptive model linking possible formation mechanisms for graphite-encapsulated nanocrystals to processing parameters
}

\author{
B. R. Elliott, J. J. Host, and V.P. Dravid ${ }^{\text {a) }}$ \\ Department of Materials Science and Engineering, Northwestern University, Evanston, Illinois 60208 \\ M. H. Teng \\ Department of Geology, National Taiwan University, Taipei, Taiwan, Republic of China \\ J-H. Hwang \\ Department of Materials Science and Engineering, Northwestern University, Evanston, Illinois 60208
}

(Received 3 September 1996; accepted 28 April 1997)

\begin{abstract}
New and modified mechanisms are proposed to account for detailed observations of carbon encapsulation of $\mathrm{Fe}, \mathrm{Ni}$, and Co nanocrystals. The mechanisms are based on aerosol and gas phase chemistry and on the catalytic effects of transition metals. Two parameters are found to qualitatively dominate production: the local-path carbon-to-metal ratio (LCM) and the global carbon-to-metal ratio (GCM). LCM's select which mechanisms are active along each pathway within the reactor. The GCM places bounds upon and determines the weighting between different LCM's and thus determines the distribution of different nanoscale products within the collected, macroscopic product. A two part processing parameter $\rightarrow$ mechanism $\rightarrow$ product map links the components. The generality of the model is discussed throughout with reference to related processes and the encapsulation of other materials.
\end{abstract}

\section{INTRODUCTION}

Encapsulation of nanocrystalline materials and the robust protection it provides has received considerable attention in recent years for both its scientific and technological implications. Being a young field, many potential applications have already been proposed in biomedicine (immunoassay, MRI contrast agent, drugdelivery ... ), cosmetics, recording media, and security (anti-counterfeiting magnetic tags). The key for many of these applications is the ability to package magnetic materials in single domain, nanoscale packets that are protected from the environment. To realize these possibilities the production of large quantities of encapsulated material must be possible.

It is the objective of this work to draw from the previous work, models, and the present investigation to present a descriptive model capable of guiding future research, equipment design, and manufacturing control through qualitative identification of the processing conditions that activate different mechanisms for the production of their associated encapsulated products.

The task of building and discussing a comprehensive encapsulation model is broken into seven sections. Section I reviews the previous work in the field. Section II critiques the previously presented encapsulation mechanisms. Section III presents the two dominant processing parameters and their associated ideas in

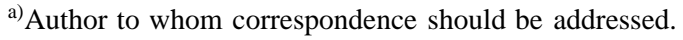

detail. It will show how both the local and global carbon-to-metal ratios are needed to understand which of three collected product types are expected, the relative weighting of different encapsulation morphologies in the collected product, and which conditions locally activate each nanoscale mechanism responsible for its associated nanoscale constituent. A three-stage processing parameter: nanoscale mechanism-nanoscale product-collected product map is presented. The schematic is broken into two parts corresponding to the two dominant processing parameters. Stages 1 and 2 of the model are then discussed in detail using part 1 of the map. Section IV addresses the nanoscale constituents that form the building blocks for these collected products. Each encapsulated, nanoscale constituent is cataloged with references to previous work by other groups. Section V discusses the modified and new nanoscale mechanisms used to explain the formation of the nanoscale constituents. In Sec. VI the three collected product types are described, and stage 3 of the model is discussed using part 2 of the map. Section VII illustrates the difference between the local and global carbon-to-metal ratios (and the implications for process design) by resolving a paradox in the number of graphite layers observed on particles.

This model was originally developed for $\mathrm{Fe}, \mathrm{Ni}$, and Co produced in the tungsten-arc (W-arc) process. Extension to other elements and development of the appropriate routes for those elements have been included based on fewer experiments but with extensive support 
from the literature already present for those elements. Throughout the text, we mention the applicability of the model to the different processing routes (W-arc, graphite arc) and the encapsulation of other materials.

\section{A. Carbon-carbon arc}

Traditionally, fullerene research utilizes a graphite anode-graphite cathode arc evaporation process known as the Krätschmer-Huffman process. Buckytubes grow at the end of the nonconsumable electrode (cathode), while the evaporated debris consists of fullerenes of various sorts, graphite flakes, and a large amount of carbonaceous debris. A modified version of this graphitegraphite arc process produced the first encapsulated species as a minority component of the carbonaceous arc products. One of the graphite electrodes (typically the anode) is bored out and filled with metal or metaloxide powder. The arc consumes both the stuffed powder and carbon rod to deposit a powdery arc product on the cathode and chamber walls which is then collected. Depending on the elements stuffed inside the anode, the collected product will contain small amounts of either the desired graphite-encapsulated metal or metal carbide crystallites, or unencapsulated metal-carbide crystallites. These nanoscale products are mixed within the amorphous carbon and graphite-like debris (e.g., nanotubes, fullerenes, graphite flakes). The process is characterized by a very high carbon supply in the arc plume, comparatively long cooling times for the metallic and carbon species, and continued growth/reaction during ion bombardment within the soot that collects on the cathode (the only place where some of the nanoscale products have been observed).

The graphite arc type processes have been very successful scientifically. Examples of isolated encapsulation of various rare earth carbides as well as transition metals $(\mathrm{Fe}, \mathrm{Ni})^{1-3}$ suggested new possibilities and launched efforts to identify the conditions that promote formation of such novel nanostructures. Insight into the fundamental processes has continued at a rapid pace. Baker-Rodrigues ${ }^{4,5}$ and Amelinckx ${ }^{6}$ began with explanations of how catalytic particles could lead to graphite fiber growth and graphite spring tubes. Majetich et al. ${ }^{9}$ were one of the first to publish a phase segregation explanation for encapsulation and based some of their findings on the distribution of nanoscale products within their reactor. Their results, like ours, indicate that the timing and degree of cooling influence the morphology of the resultant nanoscale product and particularly the crystallinity of the carbon. Saito et al. ${ }^{7}$ and Seraphin ${ }^{8}$ offered the first qualitative encapsulation models that invoked different mechanistic paths to produce different product types.
There are a few drawbacks to the graphite arc processes. First, the small yield of encapsulated product has proved sufficient for ground-breaking proofof-concept work; however, strong industrial investment seems contingent on the development of a scalable production method with higher yields. Second, the process is out-of-control in the manufacturing sense. The critical parameters for reproducible particle size distribution, number of graphite layers per particle, and quantity are not under the direct control of the experimenter. Third, previous models were not yet advanced enough to predict the desired processing conditions or capable of mapping macroscopic parameters to microscopic and nanoscale product types.

The stuffed anode systems were designed to make graphite-like products and were slightly modified to prove that encapsulation could occur. Geometrical calculations indicate that it would take less than $6 \mathrm{wt} . \%$ (24 at. \%) carbon to form one contiguous graphite coating around $10 \mathrm{~nm} \mathrm{Ni}$ nanocrystals and less than $2 \mathrm{wt} \%$ (9 at. \%) for a $30 \mathrm{~nm}$ particle. The traditional graphitegraphite arc process involves significantly more carbon ( 90-100 at. \%). This extra carbon is responsible for the formation of carbonaceous debris, which is the most difficult of the undesirable components to eliminate. Moreover, it is at present virtually impossible to eliminate carbon debris without affecting the encapsulated product. Thus it became desirable to design and build a new system that is more optimized for encapsulation and minimizes the excess carbon that causes so many yield and separation difficulties downstream.

\section{B. Tungsten-arc process}

The $\mathrm{W}$-arc and $\mathrm{W}$-blown arc ${ }^{10-12}$ processes provide better process control and improve both quantity and quality of the encapsulated products while lowering the carbonaceous debris. A sketch of our first generator and collector is shown in Fig. 1. The tungsten arc process differs significantly from the traditional graphite arc process. It is distinguished by the flexibility of the processing parameters, the electrode configuration, and the type, composition, and amount of the collected product. $^{11,12}$ These differences have forced us to rethink the Saito-Seraphin encapsulation model. ${ }^{8,13}$ New observations have led us to further refine the multiple mechanisms that may be operative and identify the general processing conditions that lead to the variety of observed nanoscale products.

The $\mathrm{W}$-arc method and the $\mathrm{W}$-blown arc method use a 0.25 inch sharpened tungsten cathode poised (usually concentrically) above a much larger, 2 inch diameter anode crucible. The crucibles are made with varying geometries of metal pools in the center of yttria-lined, 


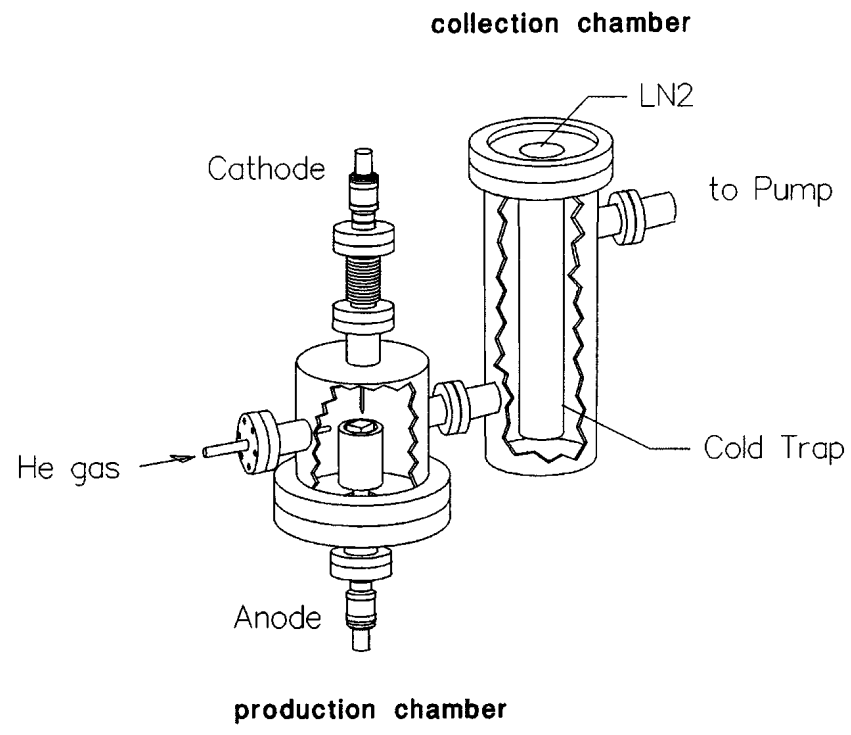

FIG. 1. First generation, blown tungsten arc reactor for production of graphite-encapsulated nanocrystals.

water-cooled copper crucibles or graphite crucibles. The arc strikes only the center of the anode on the melt pool that forms there. The plasma may envelop any other structures that protrude into the center of the anode design. Ion bombardment of the soot or other products does not occur in the $\mathrm{W}$-arc method since the product is rapidly removed from the arc vicinity by strong blowing or large convection currents. ${ }^{12,14}$ Undesirable nanotubes and graphite flakes can be virtually eliminated, and fullerenes and amorphous debris greatly reduced by the right choice of processing conditions. The macroscopic metal-carbon ratio in the gas phase can be controlled from pure metal to extremely high carbon concentration by varying the crucible design or introducing carbon in some other manner (e.g., gas). Such design choices can vary the carbon supply in the center of the arc relative to the carbon supply in the outside shell of the arc plume and/or in the chamber gas.

Most of our experiments were conducted on transition metals ( $\mathrm{Fe}, \mathrm{Co}$, and $\mathrm{Ni}$ ). Pure metal, unencapsulated particles have been formed without the addition of carbon. With the addition of carbon, protective graphite layers were present regardless of the average nanocrystal particle size $(5-100 \mathrm{~nm})$. Most of the nanocrystal ferromagnetic particles $(<40 \mathrm{~nm})$ were coated with $3-5$ graphite layers per nanocrystal. Some larger particles within each run had a large number of layers $(\sim 10-15)$. Qualitative observations find the number of layers to be sensitive to the particle size within a given run, but variable between different processing conditions. Zhou et al. found a similar dependence in their graphitegraphite arc process. ${ }^{15}$ The quality of the protective layers produced in the $\mathrm{W}$-arc method was judged by exposure to aqua regia, nitric acid, and other metal solvents. The wt. \% yield after the acid wash is variable, but tracks with controllable parameters. For example, low carbon content runs often had low post-wash yields and a qualitatively lower number (2-3) of graphite layers per nanocrystal. The wt.\% yield also did not change after the first acid wash. Even after months of additional exposure to aqua regia, the encapsulated product remained. Specific results of our work are published elsewhere. ${ }^{10,12,16}$

\section{Previously proposed nanoscale mechanisms}

Based on observations of the graphite arc (or Krätschmer-Huffman) method, some encapsulation mechanisms have already been proposed. Saito et al. proposed a $\operatorname{model}^{7}$ that starts with a metal-carbon cluster expelling some carbon to the surface as it crystallizes and, depending on the speed of the surface nucleation of graphite, resulting in either encapsulation or catalyzed nanotube formation. Single walled tube formation (SWT) occurs instead of encapsulation if the initial nucleation is so fast that some nuclei form with their $c$-axis parallel to the particle surface, resulting in a sea-urchin structure. In the Saito model, SWT formation proceeds from carbon addition at the base of the tube as additional carbon is expelled from the particle. Generally this should result in a "sea-urchin" carbon structure around a carbide particle. The growth ceases when the particle is no longer expelling carbon to the surface.

Seraphin proposed a similar model ${ }^{8}$ of SWT formation with the carbon source being a catalyzed gas phase reaction at the particle surface. In this model, tube growth stops when the particle cools sufficiently to thermodynamically expel carbon to the surface in amounts that seal the active surface in a graphite capsule. The catalyzing core particle is typically a metal-carbon alloy rather than a carbide. Seraphin also addressed the "open space" problem for encapsulated particles, suggesting that the nucleation and growth occurs on the inside of the capsule after initial nucleation of the outermost layer on the particle surface. In her model, the open space results from the expulsion of carbon from the particle.

\section{CRITIQUE OF THE SAITO-SERAPHIN MECHANISM}

The main difficulty with the Saito-Seraphin type encapsulation model is the explanation of "open space." Saito's model does not address this problem at all. Seraphin's model explains a gap as the result of the formation of graphite layers from expelled carbon and the resulting shrinkage of the core material. Shrinkage may play some role, but its role would be greatly 
minimized if the layer construction proceeds outside-in as currently proposed by Seraphin.

If graphite layers instead form on the outside of the shell where it cannot reduce the gap, it would still be difficult to explain the "open space" by mass loss from the core to shell. Figure 2 presents a geometrical calculation of maximum gap size between the shell and core, assuming the first layer formed at the diameter of the cooling carbon-saturated globule and all further volume loss occurred from carbon expulsion to the exterior of the first formed layer (inside-out growth). Additional carbon that remains in the core (e.g., in metal solid solution or carbide) would not contribute to the gap formation and is disregarded. Excess carbon is the amount of carbon present in the cluster above the saturation limit of that phase (metal or carbide). Note how difficult it would be to even detect a gap unless the particles were very large $(>100 \mathrm{~nm})$ or the initial core material was well over $20 \%$ excess carbon by volume after the formation of the first layer of graphite. The gap is never a sizeable fraction of the core particle until more than $50 \mathrm{vol} . \%$ of the initial particle is carbon. To form a gap of just $2 \mathrm{~nm}$ on a $10 \mathrm{~nm}$ particle would require the singly encapsulated core to be about 50 vol. \% excess carbon, with all the gap on one side, and only if no layers form on the interior of the shell. Shrinkage from mass loss to the shell may play a role only in creating some open space for inside-out growth, but it cannot explain large open spaces. If outside-in growth occurs instead, the core volume lost by carbon expulsion would be exceeded by the volume occupied by the new internally added graphite layer for nearly all alloy compositions. New layer formation would require the crystallites above to be "jacked up." Thus, outside-in layer formation

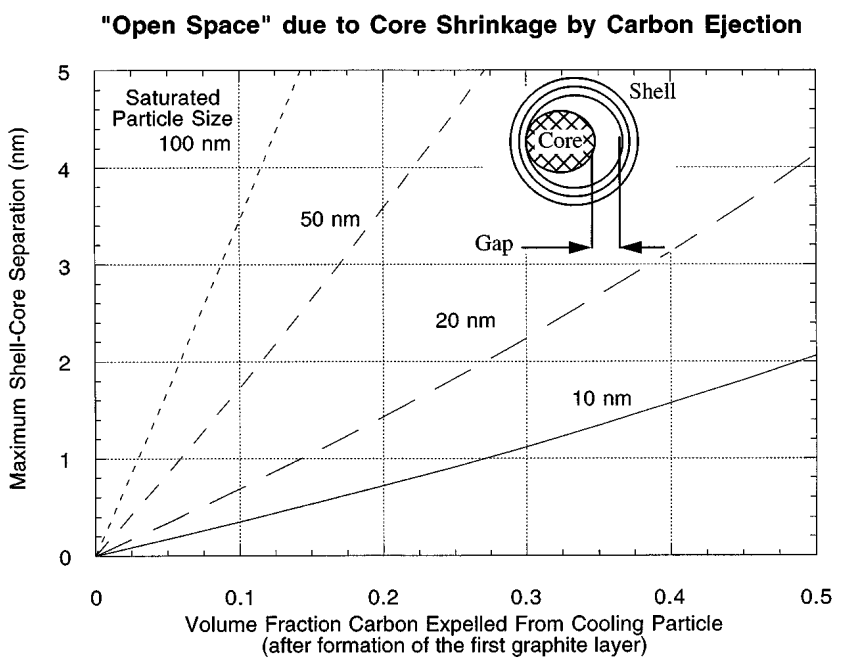

FIG. 2. Gap size versus expelled carbon content of the original alloy globule versus globule size. should result in a tightly constrained morphology rather than open space.

Any open space due to thermal shrinkage of nanocrystals after encapsulation would also be negligible. Calculations indicate the shrinkage would be about $2-3 \%$ of the original high temperature volume which is less than $1 \AA$ on the diameter of $10 \mathrm{~nm}$ metal particles. Moreover, the thermal contraction of the graphite shell is larger than most materials, which means that thermal contraction should help to close, not open, the gap.

\section{LINKING PROCESSING PARAMETERS TO MECHANISMS AND PRODUCTS}

The model we propose is simple in concept. Dynamic inhomogeneities in the reactor set up a number of competing spatial pathways. There are multiple pathways and multiple mechanisms operative in each reactor. Kinetics selects the local conditions, but it is local thermodynamics that typically dominates the outcome of each mechanism. The notable exception is the crystallinity of the carbon. In our model, the mechanism responsible for the formation of the first encapsulation layer typically determines the final encapsulation morphology of the individual particle. Thereafter the shell builds upon itself, replicating the morphology of the initial shell. Thus after the formation of the first layer, the type of core (metal, alloy, or carbide) may be less relevant for further growth.

Moreover, we propose that the multiple encapsulation mechanisms, presented below, vary their dominance with controllable processing parameters. Other authors have noted the importance of temperature, pressure, and other parameters. In particular, we believe the catalytic role of transition metals has been understated for encapsulation and can exaggerate the effects of temperature and pressure by varying the activity of the catalytic surface. We agree with previous work that these parameters can influence the outcome of any one physical pathway and particularly the crystallinity of the carbon coatings. ${ }^{9}$ We believe these parameters (T, P, catalytic action, etc.) do so by altering the dominant mechanism that is operative on that physically existing pathway to collection.

The model is distinguished, however, by the fact that only two dominant processing parameters are required to qualitatively capture the entire processing parameter-mechanism-product relationship. The two conceptual processing parameters are the (1) local path carbon-to-metal ratio and (2) global carbon-to-metal ratio. Local path carbon-to-metal ratio takes the viewpoint of the individual particle or group of particles that have the same local conditions along the same spatial pathway. The local path includes not just the carbon and metal present in the initial cluster (stage 1), but includes 
the agglomeration of clusters and atomic deposition that occurs in the gas phase (stage 2) on the way to collection (stage 3) (see Fig. 3). The global carbon-tometal ratio, on the other hand, limits which sets of local conditions can even occur. It forces an average carbonto-metal ratio on the spatial pathways around which the inhomogeneities of the process deviate. In this way the global ratio weights the frequency of each nanoscale constituent within, and thereby the morphology of, the final collected product formed in stage 3 (see Fig. 4).

The relation between controllable process parameters (temperature, evaporation rate, power, current, crucible design, aerodynamic geometry, jet speed, entrainment flow, etc.) and the local and global carbon supply are too reactor and process specific to provide detailed specifications for general use. Optimization surfaces that link the multiple process levers to process output have been determined by experiment to more quantitatively direct operation. The readers can develop similar relations for their own systems.

The abstraction to local and global carbon-to-metal ratios, however, makes generalizations across different reactors and elements possible. Different processes cover different regimes of these two ratios, specifying the gas phase processing conditions. Different synthesis techniques that achieve similar gas phase processing conditions will have similar products. Different elements form different core structures, have different carbon

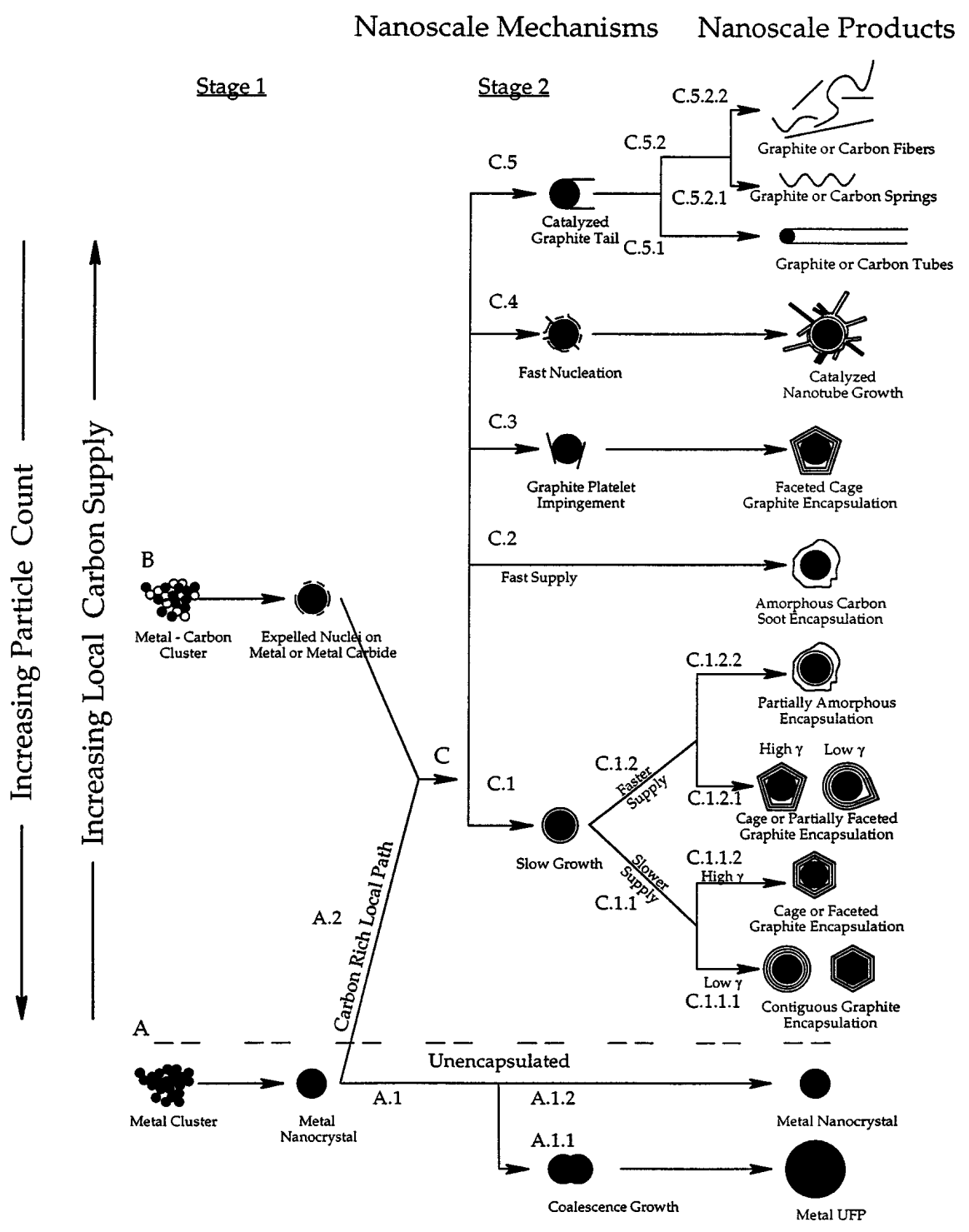

FIG. 3. Part 1 of the unified processing parameter-mechanism-product map indicating stage 1 particle formation and stage 2 carbon structure formation mechanisms that synthesize the various nanoscale products. The choice between nanoscale mechanisms seems to be predominantly selected by the local carbon-to-metal ratio along that specific path in the reactor, as indicated by the vertical axis. 


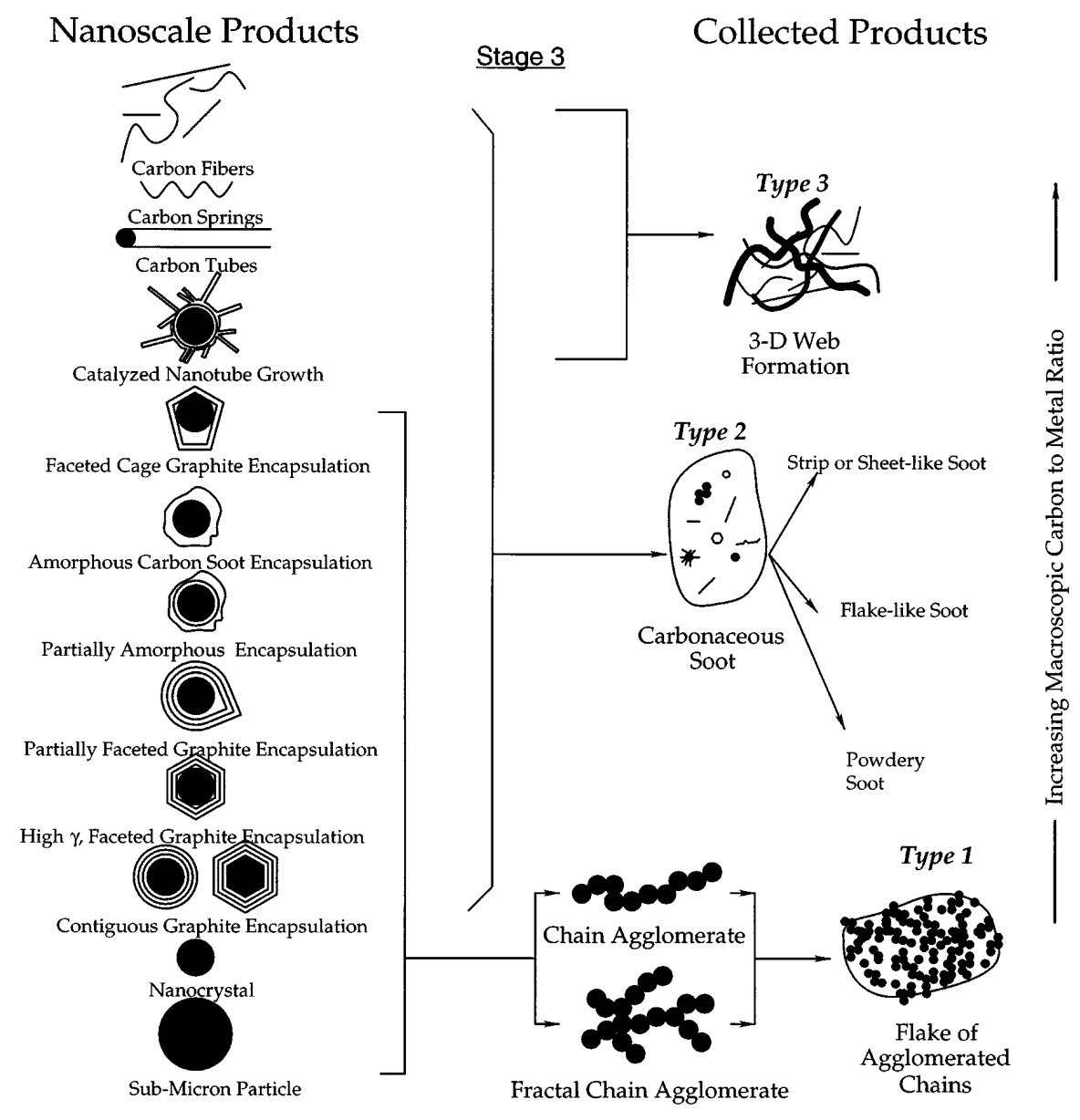

FIG. 4. Part 2 of the unified processing parameter-mechanism-product map indicating stage 3 formation of collected products. The weighting between the multiple nanoscale products and other carbonaceous debris is sufficiently limited by the global metal-to-carbon ratio to predict the type of collected product that will be formed, as shown by the vertical axis. Compositional variations within the collected product types are caused by the variation in local carbon-to-metal ratios around the global average. The dependence of one path on another limits which types of nanoscale products can even appear in the different collected products, as indicated by the brackets.

solubilities, different surface energies $(\gamma)$, and may or may not have catalytic mechanisms available to them. A schematic of our composite processing parametermechanism-nanoscale product map is presented in Fig. 3. Note that it connects with Fig. 4 as the different pathways converge at collection, causing nanoscale products to agglomerate into their collected forms. Details of the various mechanisms are presented in Sec. V and in the relevant cited references.

\section{A. Using the two schematic maps}

First note that both maps are needed to properly use the model and that they link at the right side of Fig. 3 and the left side of Fig. 4 but use different axes corresponding to the two abstract processing parameters that describe the gas phase processing conditions present. The key insight for use of this model is that the same reactor has multiple physical processing pathways within it. Each can have different local carbon-to-metal ratios, quench rates, particle densities, recirculation histories, and encounter different inhomogeneities. Thus, multiple nanoscale mechanisms are active at the same time along different paths, creating a mixture of nanoscale constituents that later agglomerates into the collected products described in the literature and shown in Fig. 4. The choice between nanoscale mechanisms seems to be predominantly selected by the local carbon supply in that particular location within the reactor (see Fig. 3). The weighting between multiple nanoscale products and the collected products they agglomerate into seems to be selected by the global metal-to-carbon ratio provided (see Fig. 4). This difference in relevant axes provides a natural split in the schematic representation of this model, emphasizing the dominance of the local carbonto-metal ratio in stages 1 and 2 (Fig. 3) and the global carbon-to-metal ratio in stage 3 (Fig. 4). By manipulating the local paths through process parameters and 
reactor design, certain mechanisms can be selected to dominate in the reactor as a whole, given an appropriate selection of the global carbon-to-metal ratio.

\section{B. Stage 1-Particle formation}

Cluster formation occurs very rapidly within the arc plume. The local carbon/metal atom ratio at the point of formation can vary greatly with anode geometry and process design. In the typical $\mathrm{W}$-arc process, the center of a composite crucible anode is entirely molten metal that, depending on the design, may or may not be saturated with carbon. This allows some control over the initial ratio in metal-carbon clusters or allows the formation of essentially pure metal clusters. Other process geometries, including the powder packed anode in the graphite arc process, predominantly evaporate carbon atoms with some metal atoms. Those designs result in the formation of metal-carbon clusters and carbon-rich gas.

Both routes are indicated on the far left of the schematic in Fig. 3 labeled A (pure metal clusters) and B (metal-carbon clusters). These clusters are subject to aerosol coalescence and agglomeration. ${ }^{17-19}$ The Wblown arc process has a log normal size distribution with $\log$ normal standard deviation of $\sigma=1.35-1.37$. $\sigma=1.35$ is the expected distribution for self-similar coalescence growth. ${ }^{17,20,21}$ Wider distributions indicate either deviation from self-similar coalescence or the existence of multiple particle growth paths. Narrower distributions could not be explained by coalescence growth.

Without the addition of any carbon, unencapsulated pure metal particles are formed by either of two routes labeled A.1.1 and A.1.2 in the bottom of Fig. 3. in A. 1.2 the coalescence stops and agglomeration begins with nanometer sized clusters or the metal density within the gas is so low that coalescence of the particles proceeds slowly and ceases upon collection on a cold surface. The boundary between coalescence and agglomeration is temperature and surface quality (oxide, carbon shell, etc.) dependent. In A. 1.1 coalescence growth proceeds beyond the nanophase regime as the density of particles in the gas is higher (faster metal evaporation or slower dilution in the gas phase via jet blowing or mixing) and the particles stay hotter for longer times, allowing submicron particles to build up at the expense of smaller nanoparticles in a manner analogous to cluster formation from atoms. This process proceeds by well understood aerosol coalescence processes and is included for completeness of the processing model. ${ }^{17}$

With the addition of carbon new products can be formed. Metal-carbon clusters behave in a manner analogous to pure metal coalescence growth, but their growth is quickly limited to the nanometer regime as the temperature falls and carbon is expelled to the surface.

Global carbon can be provided four ways: (1) dissolution of carbon in the metal pool either by use of a metal-carbon alloy as the initial source material or concurrent alloying with the crucible material, (2) co-evaporation of a graphite crucible, foil, or other carbon source inside the arc plume, (3) sublimation of any non-graphitic carbon components from the porous graphite crucible into the chamber gas away from the arc plume, and (4) use of a secondary carbon source unrelated to the primary arc that introduces carbon for gas phase chemistry (e.g., in a blowing or entrainment gas, or elsewhere in the reactor).

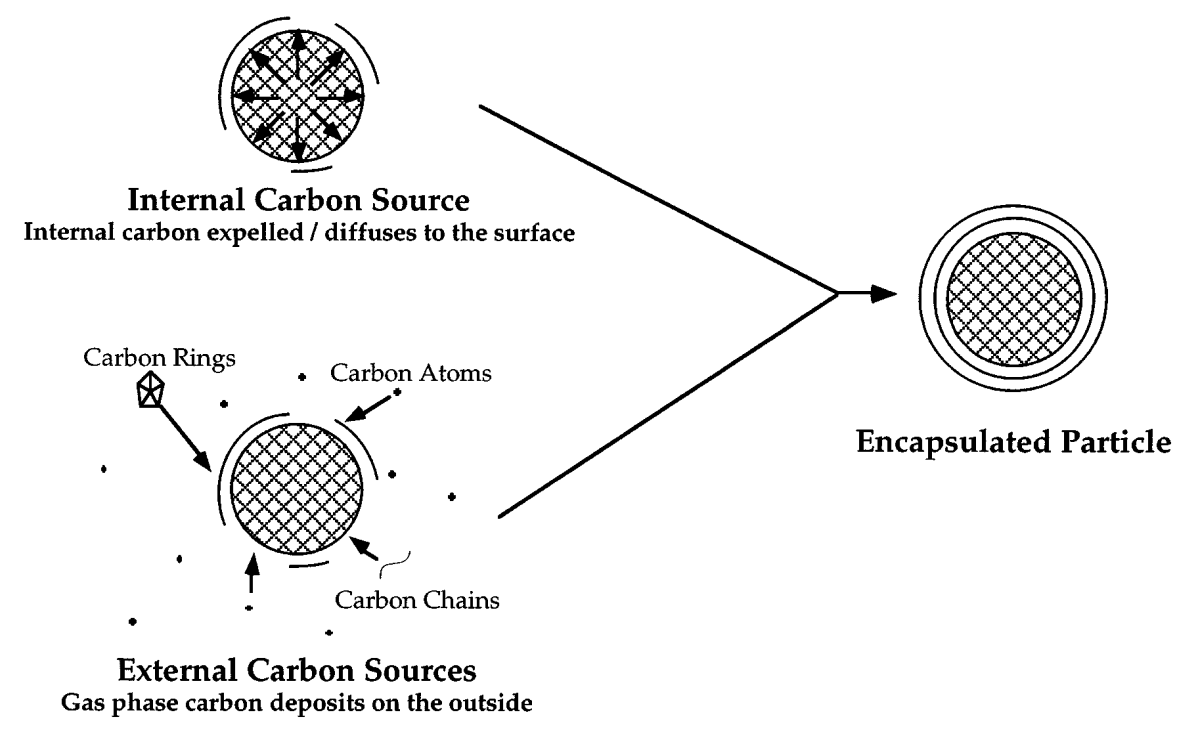

FIG. 5. Internal and external carbon sources. 
From the viewpoint of the particle there are only two local sources of carbon: internal and external, as illustrated in Fig. 5. During cooling, the clusters or globules crystallize into nanocrystalline particles and any excess carbon atoms rapidly diffuse to the surface. Encapsulation proceeds on saturated particles by expulsion of carbon to the surface during crystallization of the metal or carbide core labeled B in Fig. 3. This is an internal carbon source. If the cluster is not supersaturated at any temperature, then graphite must be deposited on the surface by an external carbon source or the particle will remain unencapsulated. In high local carbon-tometal concentrations, evaporated carbon deposits on the nanocrystals even as carbon is being expelled (i.e., both internal and external sources can be active).

There are two types of external carbon sources: atomic and molecular. The most common is thought to be atomic carbon deposition (A.2). Alternately, gas phase nucleation of graphite nuclei, carbon rings, or small sheets is possible when the carbon supply is high and time for formation is available. Carbon atoms, carbon rings, nuclei, or small sheets then collide and deposit on the particles suspended in the gas. Carbon deposition occurs if any location along the particle pathway has a high carbon supply in the gas. For example, the outside shell of the arc plume can have a larger local carbon content than the interior of the arc in some crucible designs. Inhomogeneities are observed in the density and flow of the arc plasma. Thermodynamics dictates that large subcritical nuclei exist in multi-component, single phase melt pools even at low carbon contents. Upon being struck by the arc, the local carbon content in the gas phase may be high enough to nucleate graphite or other forms of carbon directly from the locally dense carbon clusters. A complete description of other inhomogeneities is found in Host et al. ${ }^{10}$

\section{Predicting the phase of the core- A selection rule}

Currently we are unaware of any published theories that correctly predict which elements encapsulate as metals, which as carbides, and which will not encapsulate at all. Previous efforts have considered the melting point, vapor pressure, or merely observed some of the phenomena that work or do not work. While such a rule is useful, this model does not specifically rely on what the selection rule actually is. Nonetheless, some noncontroversial generalities seem reasonable and consistent without arguing the fundamental mechanism.

If carbon is present in the arc (as opposed to introduction well downstream), the local concentrations seem to determine the phase (metal or carbide) as per the phase diagram. The phase of the core or bare nanocrystal does not seem to depend on the carbon concentration or the means of introducing the carbon into the arc. Presumably this is because it is atomically dismembered in the arc plasma. A survey of the literature and our own experience $\left(\mathrm{B},{ }^{22} \mathrm{Cr},{ }^{23} \mathrm{Gd},{ }^{24} \mathrm{La},{ }^{25} \mathrm{Mn},{ }^{23,26} \mathrm{Mo},{ }^{23} \mathrm{Nb},{ }^{23}\right.$ $\mathrm{Si}, \mathrm{Ti}^{27,28} \mathrm{~V},{ }^{29} \mathrm{Y},{ }^{27,28}$ and $\left.\mathrm{Zr}^{29}\right)$ indicate that it is difficult to introduce carbon in an arc without the formation of stable carbide phases. Metal cores have been seen only in systems that do not form thermodynamically stable carbides $\left(\mathrm{Co},{ }^{10,30-32} \mathrm{Cu},{ }^{33} \mathrm{Fe},{ }^{10} \mathrm{Ni},{ }^{10,32}\right.$ and $\left.\mathrm{Pd}^{34}\right)$. One possible exception is reported for $\mathrm{Mn}^{35}$; however, the dispute is based on a single electron diffraction pattern and was not confirmed with x-ray diffraction as was done in the papers that report $\mathrm{Mn}$ carbide ${ }^{23,26}$ encapsulation. It is noted that metastable $\mathrm{Fe}_{3} \mathrm{C}$ occasionally forms instead of metallic $\mathrm{Fe}$ in high carbon supply processes (e.g., Ref. 32). Metastable $\mathrm{Co}_{3} \mathrm{C}$ and $\mathrm{Ni}_{3} \mathrm{C}$ have also been reportedly encapsulated as minority components. ${ }^{36} \mathrm{We}$ have not observed any of these metastable forms.

The rule we present is this. If there is a thermodynamically stable carbide at room temperature it seems to form instead of the metallic phase and forms preferentially to the formation of an encapsulated shell. In some cases carbide formation may prevent encapsulation by consuming too much carbon in low carbon arcs. In other cases the lack of catalytic activity of the carbide core may further inhibit the formation of the first graphitic coating on the surface. A more predictive and fundamental explanation for this selection rule is being developed and will be presented at a later date.

This empirically based, thermodynamically dominated core phase selection rule still provides some guidance. It is a strong indication that the internal carbon source dominates the formation of the initial encapsulation layer when carbon is introduced in the nucleation zone. Processes that circumvent the intimate and hot contact of the elements may circumvent this rule. It is hoped that introducing carbon downstream from the initial arc would allow encapsulation of carbide formers in their metallic state. This has not been tested. Alloys that suppress carbide formation in their ternary phase diagram but contain the desired element may prove useful as substitutes which can encapsulate without forming carbides.

\section{Stage 2-Carbon structure formation}

At label C in Fig. 3, nucleation of graphite has begun either by catalytic or heterogeneous nucleation on the particle surface, or by homogeneous nucleation of carbon rings in the gas phase. Once the initial cluster has the first carbon layer on its surface, the particle has less impact on the future microstructural developments. For most cases the subsequent layers mimic the structure of the first. 
The final encapsulation morphology of an individual particle or group of particles traveling together depends on the local conditions of the physical pathway between nucleation and collection. The local conditions activate a dominant nanoscale mechanism along that pathway. Kinetics dominates the activation process through the rate of carbon deposition on a particle, the rate of graphite nucleation, the rate of homogeneous gas phase nucleation of carbon structures, etc. Once chosen, however, local thermodynamics dominates the outcome of that mechanism through phase separation, crystal structure (e.g., high pressure phase expected for small particles due to Gibbs-Thompson, carbide versus metal), and particle-shell versus vacuum surface energies.

By surface energies we refer to comparative Gibbs free energy of the particle in contact with vacuum or in contact with the surface state of carbon (graphite in this case). The surface energy is important because it determines whether the energy to form a defect in the carbon structure is higher or lower than the energy required to create two new interfaces (metal-vacuum and carbon-vacuum). A low core-graphite surface energy - low $\gamma$-(i.e., high core-vacuum surface energy) would make a defect in the graphite more likely. A high core-graphite interface energy-high $\gamma$-would allow separation of the graphite from the particle surface since graphite prefers to grow in straight, nondefective sheets.

At the highest local carbon supplies the particles streak through a carbon filled chamber gas. Besides the particulate products we are focusing on, additional types of pure carbon (graphite flakes, tubes, balls, etc.) form in increasing abundance. The local carbon-to-metal ratio is harder to picture in this high carbon regime. It is easier to think in terms of the increasing number of particles required by mechanisms C. 5 to C. 2 to operate. In the C. 5 series of mechanisms, the few particles that are around may catalyze a solid or hollow carbon fiber in their wake. At slightly lower local carbon contents, graphite flakes homogeneously nucleate in the gas phase and carbon atoms rain down on passing particles. Fast nucleation (C.4) on particle surfaces or the impingement of graphite sheet nuclei can result in some sheets growing radially away from the particle, resulting in a sea-urchin type structure. In some sections of the reactor, graphite sheets have more time to grow before collision with a particle. These impinging flakes can be larger than the particles themselves (C.3), leading to faceted cages that enclose large open spaces around particles as the flakes grow together with further additions of atomic carbon. On other flight paths the particle may become inundated with carbon too quickly to organize graphitic shells (C.2). This inundation can result from rapid deposition or rapid quench expulsion of carbon. Either type of inundation produces a particle shrouded in amorphous carbon (C.2).
The C. 1 series of mechanisms are the primary products formed in $\mathrm{W}$-arc processes. Here the branching from the initial cluster depends on the kinetics of carbon supply to the shells. The supply can be internal (expulsion) or external (deposition). For slower processes the final form depends on the difference between the particle-graphite interface energy and vacuum surface energies $(\gamma)$, and the energy to bend the graphite sheets. For low $\gamma$ interaction (C.1.1.1), the graphite hugs the surface, forming a contiguous shell that exactly mimics the surface morphology of the particle below. Spherical particles form spherical shells and faceted particles form faceted shells. For higher $\gamma$ interactions, the nuclei break from the surface as they grow, only to intersect a short distance from the surface. On the faster supply branch (C. 1.2), there are two possibilities. In one case there is a single faster deposition speed (C. 1.2.1) which causes a few nuclei to grow and kinetically break away from the surface of even low $\gamma$ surfaces. As they shelter the particle surface from further external deposition, the nuclei grow away from the surface, no new nuclei grow below, and the dangling nuclei intersect a larger distance from the surface, enclosing a small amount of open space. High $\gamma$ surfaces would have their characteristic faceted structure with a small amount of open space added. Low $\gamma$ cores would still have intimate contact with any nuclei that did not grow rapidly enough to peel away and appear partially faceted in the section that did grow rapidly. The second branch (C. 1.2.2) on the faster side assumes a two-step carbon supply. One or even a number of shells fully organize as per the routes labeled C.1.1.1, C.1.1.2, or C.1.2.1. Then the local carbon supply steps up to a higher rate. It shrouds the particle in more carbon than nucleates as crystalline graphite in the remaining time or at low temperature, resulting in a partially amorphous encapsulation similar to mechanism C. 2 .

\section{NANOSCALE MORPHOLOGIES}

Results from our own experiments are combined with data from the literature on transition metals and rare earth carbides to form a catalog of the morphologies that must be explained by a comprehensive model. At this point there is no need to distinguish between pure metal, metal-carbon alloy, and carbide particles. Table I presents a list of the nanoscale products found in all of the arc processes used to form encapsulated products. A brief description of each morphology is included in the table along with references. Most references include TEM pictures of the indicated morphology.

The carbon arc literature has focused on types 1 to 4 and we defer to their detailed treatments. ${ }^{4,5,7,13,37,38}$ Nearly all the ferromagnetic particles exhibit a spherical shape with contiguous graphite encapsulation 
TABLE I. Catalog of the various encapsulated species.

\begin{tabular}{|c|c|c|c|c|}
\hline Type & Nanoscale morphology & Picture & Description & Ref. no. \\
\hline 1 & $\begin{array}{l}\text { Carbon or graphite } \\
\text { fibers }\end{array}$ & & $\begin{array}{l}\text { Long carbon chains } \\
\text { grown from particles }\end{array}$ & $4,5,37,48,49$ \\
\hline 2 & Graphite springs & & $\begin{array}{l}\text { Helical carbon chains } \\
\text { or tubes grown } \\
\text { from particles }\end{array}$ & 5 \\
\hline 3 & Graphite tubes & & $\begin{array}{l}\text { Graphite tubes or a } \\
\text { string of beads } \\
\text { extend from metal } \\
\text { particle at the tip }\end{array}$ & $4,5,13,37,50$ \\
\hline 4 & $\begin{array}{l}\text { "Sea urchin" or } \\
\text { catalyzed nanotube } \\
\text { structure }\end{array}$ & & $\begin{array}{l}\text { Graphite nanotubes } \\
\text { extend from metal } \\
\text { core }\end{array}$ & $7,13,37,38,51,52$ \\
\hline 5 & $\begin{array}{l}\text { Faceted graphite cage } \\
\text { encapsulation }\end{array}$ & & $\begin{array}{l}\text { Faceted cage structure } \\
\text { with "open space" }\end{array}$ & $1,2,13,25,38$ \\
\hline 6 & $\begin{array}{l}\text { Amorphous carbon } \\
\text { encapsulation }\end{array}$ & & $\begin{array}{l}\text { Nanoparticle } \\
\text { embedded in } \\
\text { amorphous carbon }\end{array}$ & 52 \\
\hline 7 & $\begin{array}{l}\text { Partially amorphous } \\
\text { carbon encapsulation }\end{array}$ & & $\begin{array}{l}\text { Nanoparticle with } \\
\text { partial or a few } \\
\text { layers of graphite } \\
\text { coating embedded in } \\
\text { amorphous carbon }\end{array}$ & 16,52 \\
\hline 8 & $\begin{array}{l}\text { Partially faceted } \\
\text { graphite } \\
\text { encapsulation }\end{array}$ & & $\begin{array}{l}\text { One section of } \\
\text { otherwise } \\
\text { contiguous graphite } \\
\text { coating, disconnects } \\
\text { from the surface or } \\
\text { underlying layers } \\
\text { and extends outward } \\
\text { as a partial facet }\end{array}$ & 10 \\
\hline 9 & $\begin{array}{c}\text { Faceted graphite } \\
\text { encapsulation }\end{array}$ & & $\begin{array}{l}\text { Faceted graphite cage } \\
\text { only tangentially } \\
\text { touches an enclosed } \\
\text { particle }\end{array}$ & 10,37 \\
\hline 10 & $\begin{array}{l}\text { Contiguous graphite } \\
\text { encapsulation }\end{array}$ & & $\begin{array}{l}\text { All graphite layers are } \\
\text { contiguous to the } \\
\text { particle surface and } \\
\text { shape }\end{array}$ & $10,11,30,31,37,53$ \\
\hline 11 & $\begin{array}{l}\text { Nanocrystal } \\
\qquad(\sim 5-50 \mathrm{~nm})\end{array}$ & & $\begin{array}{c}\text { Bare, unencapsulated } \\
\text { nanoparticle }\end{array}$ & 10,12 \\
\hline 12 & $\begin{array}{l}\text { Submicron particle } \\
\quad(<0.5 \mu \mathrm{m})\end{array}$ & & $\begin{array}{l}\text { Bare, unencapsulated } \\
\text { ultrafine particle }\end{array}$ & 10,12 \\
\hline
\end{tabular}




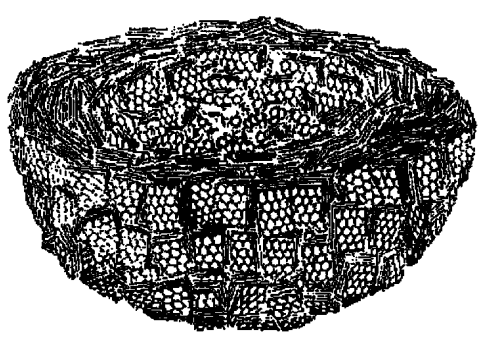

(a)

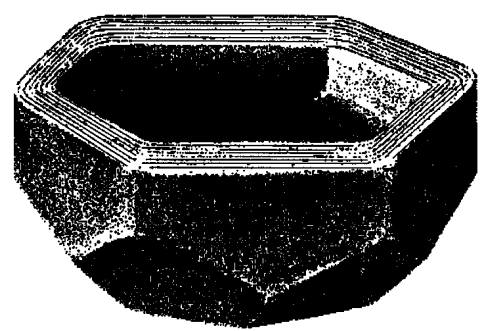

(b)

FIG. 6. (a) Cut-away of the carbon black structure shows the many graphitic platelets arranged with their $c$-axis oriented normal to the particle surface and (b) cut-away of the faceted graphitic structure. ${ }^{39}$

accommodated by line or plane defects resembling the carbon black particle structure in Fig. 6(a) and labeled as type 10 in Table I. ${ }^{10,39}$ Metal carbide particles that are themselves faceted have been observed to be contiguously encapsulated. ${ }^{37}$ This type of faceted capsule structure is also cataloged as type 10 since it exactly mimics the faceted particle. The contiguous graphite layers on particles produced by arc methods have been shown to be turbostratic, further emphasizing the highly defective nature of contiguous encapsulation. ${ }^{10}$ Within each run it is rare but possible to find spherical particles that exhibit faceted capsule structures similar to Fig. 6(b) ${ }^{39}$ This faceted morphology exhibits tiny "open spaces" between the graphite capsule and the roughly spherical core species and is cataloged as type 9. An equally rare partially faceted morphology, type 8 , can also occur on spherical particles where a short faceted section interrupts otherwise intimate contact, leaving open space between the shell and particle. Other researchers have observed an extended, faceted cage morphology encapsulating either a faceted or spherical particle and an open space that is a sizeable fraction of the enclosed particle, most notably on the rare earth carbides. ${ }^{1,2,25}$ This is more rare at lower global carbon-to-metal ratios. In the absence of carbon or at low carbon-to-metal ratios the predominant nanoscale products are metal nanocrystals (type 11) that agglomerate in chains. However, under the same conditions, collecting samples from hot surfaces in the reactor or from surfaces too close to the arc (cold walls but still hot gas) tends to reveal submicron particles (type 12), probably formed by gas phase coalescence in high metal density gas, post-collection gas phase deposition directly on the particles, and by post-collection annealing/sintering.

\section{POSSIBLE NEW AND MODIFIED NANOSCALE MECHANISMS}

This section completes our picture by modifying and proposing mechanisms that can explain each of the encapsulated nanoscale constituents. They are discussed as they activate with increasing local carbon concentration. The route labels in curly brackets correspond to the location of each mechanism in Fig. 3.

\section{A. Modified Saito-Seraphin encapsulation: Catalytic particle-Internal carbon source rroute C.1.1.1}

We propose that any layers that form as a result of carbon deposition primarily build inside-out. Layers that form as a result of carbon expulsion primarily build outside-in, jacking up the crystallite above it, or may diffuse the carbon to the surface and mimic the exterior of the shell. The initial layer mimics the particle surface morphology and subsequent layers mimic their underlying shell. A spherical particle would appear to have a spherical shell and a faceted particle would appear to have a matching faceted shell. In the case that enough space opens between the shell and core to admit another layer of graphite on the interior, then the layer does indeed form on the inside, closing the gap by $\sim 0.335 \mathrm{~nm}$. This process provides for the continued appearance of intimate contact between shell and core. In no way could this mechanism create the large "open space" gaps on the order of nanometers so easily observed in the encapsulated rare earth carbides. Initial graphitic nuclei are pictured as forming primarily from expelled carbon as the particle is quenched. The only requirement, however, is rapid nucleation of the first layer so that many nuclei form without coarsening to form facets. A catalytically active surface like that of $\mathrm{Ni}^{40-42}$ would probably be required to cause such a high nucleation rate. External carbon deposition on the shells or diffusion of carbon to the surface would then form a larger number of layers that mimic the first. By restricting this mechanism to explaining only contiguous contact encapsulation (catalog type 10), the problem of open space is side-stepped. Instead, a different, but related, mechanism is presented below to explain the open space morphologies. 


\section{B. Catalytic particle-External carbon source \{route C.1.1.1\}}

There is ample evidence in the catalysis literature, based on thermodynamic arguments, that carbon preferentially nucleates as graphite on surfaces of transition metals at temperatures well below that necessary to nucleate graphite on the surfaces of other metals. ${ }^{40-42} \mathrm{It}$ is noteworthy that the cleanest examples of encapsulation are found in $\mathrm{Fe}, \mathrm{Co}$, and $\mathrm{Ni}$ which are known catalysts for graphite formation. Growth of subsequent graphite layers would be likely to proceed in a manner analogous to deposition growth.

Support for this view is found in observations of iron encapsulation (as opposed to iron carbide formation) and encapsulation of partially sintered metallic particles. These indicate that external nucleation of graphite sheets on already coarsened metal nanocrystals may proceed independent of an internal carbon source expelling carbon to the surface.

The clear and well-defined encapsulation of metallic iron in graphite shells in the $\mathrm{W}$-arc process is not surprising. We expect the thermodynamically stable form (two phase, crystalline carbon and metal) instead of the metastable carbide if the time for achieving equilibrium is available (easier for small distances) or if the metal and carbon are separated during the cluster formation stage. Carbon then deposits on the surface of a preformed metal particle. As such, the proposed encapsulation mechanism is analogous to deposition growth of dissimilar materials, even when the "substrate" (i.e., nanocrystal in our case) and the "thin film" (i.e., graphite) may have appreciable solid solubility in each other at high temperatures or have a tendency to form compounds. The final form would be the same intimate, contiguous encapsulation (catalog type 10) found in the modified Saito-Seraphin model just discussed, but the interior particle would be essentially pure metal and the source of carbon would be dominated by gas phase deposition.

\section{Noncatalytic particle \{route C. 1.1.2\}}

Noncatalytic particles that prefer to separate the graphite from contact with the surface (e.g., $\mathrm{Cu}^{33}$ ), due to their material dependent higher interface energy - high $\gamma$-no longer balancing the bending energy, have a slightly different route from the modified Saito-Seraphin model. Here each graphite nucleus separates from the surface rather than bending to conform. Large numbers of nuclei do not form because the surface is not catalytic. The initial carbon source can be either internal or external, but it is easier to imagine external deposition. Soon after nucleation, gas phase deposition no longer reaches the particle surface in the shadow of the growing graphite sheets. These separated nuclei are near equally spaced around the surface of the particle by their diffusion fed zones which prevent the formation of nearby nuclei and result in a roughly symmetric, tightly wrapped faceted shell as they intersect a short distance from the particle surface. This would leave small $(\leqslant 1 \mathrm{~nm})$ conical spaces between a spherical particle and the graphite shell (catalog type 9).

\section{Fast, external carbon supply $\{$ route C.1.2.1 $\}$}

If only a few nuclei form, or the growth is so rapid that other nuclei do not have time to form (fast or asymmetric external carbon supply), then their intersection could occur farther from the particle and enclose a larger amount of open space. This would account for particles that are wedged into one corner of a larger, asymmetric, faceted structure (catalog type 5 high $\gamma$, faceted). Even on catalytic particles with low surface contact energies, some nuclei may kinetically separate from the core if the nuclei grow so quickly that instead of bending to conform to the surface, they grow away from the surface in the typical graphite sheet form. The remainder of the particle appears to be contiguously encapsulated because of the densely nucleated structure expected from a catalytic core. This result is a partially contiguous-partially faceted capsule structure (catalog type 8). The initial carbon can be supplied from the gas phase, core, or both. The dominant source during growth must be from the gas phase. The protruding sheet can be catalytically grown from the particle surface or by edge addition. As the sheet extends, it shadows the surface underneath, preventing further local nucleation. The dangling bonds at the end of the $\mathrm{C}_{n}$ rings eventually bend the sheet over or attract similarly protruding sheets to seal the first layer. The size of the "open space" would be related to the size of the particle from which it protruded and the rate of carbon deposition.

\section{E. Amorphous carbon encapsulation \{routes C. 2 and C. 1.2.2\}}

At even faster carbon deposition or internal carbon expulsion rates, the carbon does not organize and assumes an amorphous structure on top of a metal-carbon (M-C) alloy, compound, or pure metal particle. Under certain conditions the driving force for crystallization may be insufficient to overcome the kinetic activation barrier. We have evidence that temperature and pressure of formation greatly influence amorphous carbon formation. This is more likely to occur on noncatalytic particles or under noncatalytic conditions (e.g., low $\mathrm{T}$, incorrect P). As expected, it is most often observed at high global carbon-to-metal ratios. If there are different carbon addition rates at different times or locations in the reactor, this same mechanism can occur on top of a particle that has had time to form the first graphite layer or even a few layers before being overwhelmed with 
carbon. Such a two-step carbon deposition rate can result from different carbon concentrations in different areas of the arc plume or reactor chamber or from recirculation of particles. A two-step internal carbon expulsion rate may occur from quenching after a period of slow cooling. A dramatic increase in carbon addition rate may result in amorphous encapsulation of any surface, graphite encapsulated or not.

A second structure for "amorphous" encapsulation may be the disordered collection of tiny gas phase nucleated graphite sheets and $\mathrm{C}_{n}$ rings by the particle as it passes through carbon-rich sections of gas. Under a microscope these tiny crystals and rings would not exhibit any diffraction contrast but would be more stable than a truly amorphous local structure. An external formation mechanism (graphite nucleation in the gas phase) could also explain the often irregular amorphous encapsulation morphology. TGA experiments may be able to determine which structure is correct by searching for a graphite nucleation and a separate growth peak. The presence of such a peak would indicate a truly amorphous structure.

\section{F. Carbon ring/network impingement \{route C. 3 \}}

A hot particle that has not yet expelled its carbon, a pure metal particle, or a cold particle that has insufficient excess carbon (due to solubility or formation of a carbide) to self encapsulate could encounter larger homogeneously nucleated graphite flakes/carbon ring networks in the gas phase. As these flakes collect on the surface and grow to contact one another by further atomic addition, an irregular, faceted structure will emerge that roughly outlines the particle shape, but may include very large open spaces. This new mechanism can also explain contiguously encapsulated particles that have a secondary shell including open space that does not entirely follow the underlying shell morphology.

Free floating, flat carbon networks are most likely to occur in the highest global carbon-metal ratio processes. The rare earth carbides with large open spaces are likely candidates for this form of encapsulation since it would be difficult for the initial clusters to be so carbonrich to form both the carbide and greatly extended capsule structures. Instead, the stuffed graphite anode probably forms metal-carbon clusters on the inside of the plume above the stuffed section. Further carbon is added as it passes through the outer carbon-rich shell of the arc plume which derives from the arc striking the graphite annulus around the stuffed section. Carbon-rich convection cells swirl in various sections of the reactor chamber, giving time for semi-homogeneous nucleation of graphite flakes and other carbon structures which then collect on cold surfaces or attach to the minority carbide nanoparticles mixing in the convection cells.

\section{G. Modified Saito-Seraphin single-walled tube (SWT) growth \{route C. 4\}}

As described in their earlier work, the graphite nuclei form so rapidly that they assume semi-random orientations. Some of the crystals have their $c$-axis oriented parallel to the particle surface. Alternately, gas phase nucleated carbon rings could impact the particle such that the $c$-axis is not radially aligned. Either situation matches the starting point for the Saito-Seraphin explanation of SWT formation. The sheets grow catalytically from the surface or atomically at the ends. Eventually the dangling bonds encourage the sheet to roll in on itself and a SWT is formed. The carbon source could be from the core or gas.

\section{H. Catalyzed fiber growth \{route C.5\}}

SWT formation may well contribute to some of the tube formation. It cannot explain micron-long protrusions from nanometer particles within a web network. Combining the internal and external carbon sources and still relying on the catalytic nature of the underlying particle, the starting point for web formation is better understood. The formation of long graphite/carbon fibers is well treated by Baker and Rodriguez ${ }^{4,5}$ involving unidirectional diffusion of carbon through a leading catalytic metal particle. The spring-like morphology of long buckytubes is rationalized by Amelinckx by invoking stress considerations in a growing nanotube and accommodation of this stress by tube bending. ${ }^{6}$

\section{STAGE 3-COLLECTED BULK PRODUCT TYPES}

Stage 3 is dominated by a different processing parameter than stages 1 and 2 . The first schematic emphasized the local processing conditions. Understanding stage 3 , however, requires a global view of the process. The different local paths cannot be altered independently. The global carbon-to-metal ratio limits which sets of local conditions can occur in the reactor. It forces an average carbon-to-metal ratio on the spatial pathways around which the inhomogeneities of the process deviate. In this way the global ratio weights the frequency of each nanoscale constituent and thereby the morphology of the final collected product.

Figure 4 schematically shows the agglomeration of the nanoscale products downstream from the arc. The same encapsulated nanoscale constituents exist in different quantities within different collected product types. Similar macroscopic processing conditions can result in very different weighting between the nanoscale constituents even within the same collected product type by changing the variance of local carbon-to-metal ratios along the pathways to collection within the reactor. In addition, all three product types can be produced in the 
same reactor if the method can vary the global metal-tocarbon ratio by large amounts.

It is observed that the collected product regardless of the arc method is one of three types, depending on the global carbon-to-metal ratio: (i) web, (ii) carbonaceous soot, and (iii) particle dominated agglomerates (either chain or fractal).

Web formation occurs when a high carbon content gas is pierced by catalytically active particles. Webs consist of solid or hollow tubes of carbon. Their diameter is similar to that of the catalyzing particles from which they trail. They grow in a manner similar to the catalytic formation of carbon fibers commonly used in industry. ${ }^{43-45}$ The dominant products are carbon fibers, nanotubes, and carbonaceous materials. Web formation is always accompanied by carbonaceous soot.

Soot collects on just about every surface in the reactor. The particles and debris from the arc agglomerate in the gas and deposit on the colder surfaces. Carbonaceous soot can very in consistency from flaky or strip-like to delicate and powdery. This is the typical product found on the walls of modified Krätschmer-Huffman generators.

Particle-dominated products form chain and fractal agglomerates in the gas phase and travel to colder surfaces in the reactor by thermophoresis and convection. Here they deposit as a flaky powder. This is the desired form for the production of graphite encapsulated particles. This particle-agglomerate type of collected product has not been observed to our knowledge within graphite arc processes. The global carbon-to-metal ratio is always too high. In the W-blown arc method, much less deposition occurs inside the arc chamber since most of the products are whisked into the collector by forced convection.

The aerosol agglomeration interpretation is supported by a number of observations, such as a transmission electron microscopy (TEM) study of samples collected at a variety of distances along the blowing direction toward the collector. It indicates that particle coarsening occurs before, and agglomeration after, cooling in the gas phase. Optical pyrometer measurements through pyrex glass indicate arc plasma and melt pool temperatures greater than $2000{ }^{\circ} \mathrm{C}$. The exterior of aircooled pipes downstream from the nucleation zone is above $100{ }^{\circ} \mathrm{C}$. Expanding and quenching the gas with a helium jet decreases the particle size of unencapsulated particles by slowing coalescence. ${ }^{12}$ Recent results suggest that particle size control of encapsulated species is less sensitive than for unencapsulated particles within the same experiment. The presence of carbon on globule surfaces probably retards coalescence more effectively than the jet, as indicated by the smaller average size of encapsulated versus unencapsulated particles. Any surface close to the arc, despite its temperature, will collect large particles due to gas phase deposition coarsening of nuclei on the surface. This is taken as evidence that the nucleation and growth phase is interrupted by the surface before completion. In addition, hot surfaces tend to enhance sintering of unencapsulated particles and coagulate large particles. At an abrupt distance from the arc, chain and fractal agglomerated nanophase particles suddenly dominate on every surface, indicating an end of the nucleation and growth zone. The "choice" between chain and fractal agglomerates of smaller particles is determined by the material dependent sticking coefficient and the particle-chain approach trajectories available, as in the standard explanation of gas phase fractal growth. ${ }^{17-19,46,47}$

\section{ENCAPSULATION THICKNESS}

If local conditions are held the same and only the particle size varies, the internal and external carbon sources can be compared. The internal source is volumetric and the external source is cross sectional, but both are supplying carbon to shells that approximate the particle surface area. An internal volumetric source would result in an increasing number of layers on larger particles since volume increases faster than surface area with increasing particle size. A cross-sectional deposition source increases its collection proportional to the increase in particle surface area, so the number of layers would remain constant with particle size.

Figure 7 shows the local path excess at. \% carbon (i.e., only the carbon in the shell regardless of its source) needed to explain a 2- or 10-layer encapsulation of $\mathrm{Ni}$ metal particles. It does not assume a mechanism for formation, or where along the path of the particle it acquired carbon. The calculation is almost purely

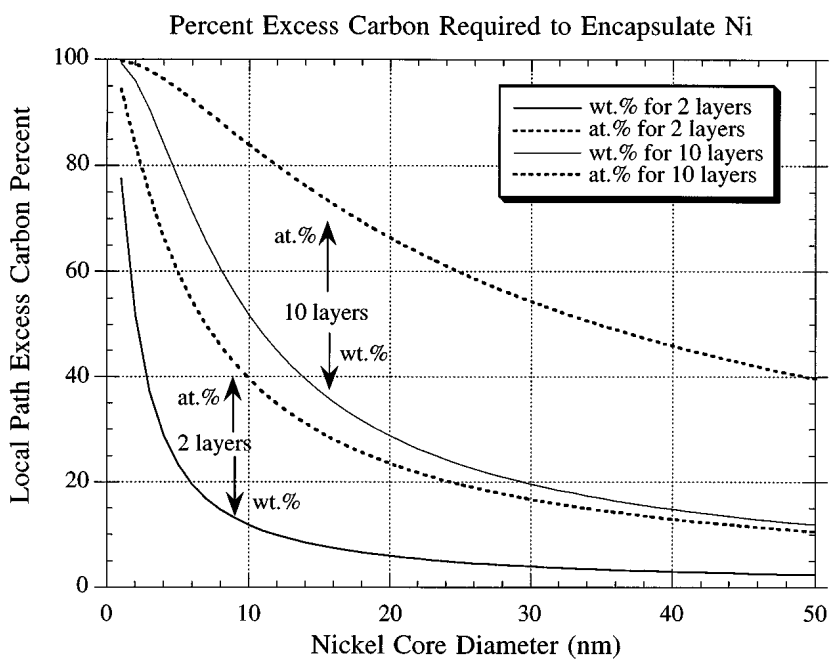

FIG. 7. Atomic and wt. \% carbon required for encapsulation changes with particle diameter and the number of encapsulation layers. 
geometrical for the at. \% lines. To calculate the total path, percent carbon (excess plus internal carbon) a number of corrections would need to be made. For example, one would need to correct for carbon consumed in solid solution (which changes slightly with size) or carbide formation in the core particle.

As plotted, the data emphasize the external carbon source. Since external collection is proportional to crosssectional area and not volume, the at. \% carbon is higher for the smaller particles but follows the constant number of layer contours shown. The data could as easily be plotted versus number of layers with constant at. \% and wt. $\%$ contours to emphasize the internal source description. Note that the same at. \% carbon needed to form 2 layers on a $10 \mathrm{~nm}$ particle forms 4.5 layers on a $20 \mathrm{~nm}$ particle, 10 on a $50 \mathrm{~nm}$ particle, and 20 on a $100 \mathrm{~nm}$ particle. This nonlinear increase in the number of layers of graphite formed around larger particles at constant at. \% is exactly the internal carbon source: volumetric source going to a surface area sink.

There is a paradox. The expulsion of carbon could account for all of the excess carbon needed to encapsulate $10 \mathrm{~nm}$ sized particles with 3-5 layers as observed except that they were found in 5 wt. \% global carbon experiments. The paradox is solved by recognizing the difference between local path and global carbon-tometal ratio. The high carbon-metal ratios required for encapsulation of small particles can be exceeded within inhomogeneities in the cluster formation region of the arc or by adding carbon along the path of the particle in the gas phase. It is the dynamic, inhomogeneous nature of the arc that even allows encapsulation at such low global carbon-to-metal ratios. We also note that the wt. \% yield of encapsulated versus bare particles fell drastically for these runs, as would be dictated by conservation of mass in a low global carbon-to-metal ratio which weighted the unencapsulated pure metal (or solid solution) pathway more than the encapsulated pathways.

There are many implications for reactor design. Super high excess-carbon-to-metal (C-M) ratios are clearly achieved in graphite arc systems but cannot be achieved in systems where a one-phase carbon saturated metal alloy is the only source of carbon. Reactors that introduce the majority of carbon after cluster agglomeration will exhibit a more uniform number of layers versus particle size. Control of the carbon content of the gas phase may be particularly desirable for forming many layers on small particles. Solid solubility and carbide formation reduce the number of shell layers formed on a cooling cluster by retaining more carbon atoms in the core. A two-phase initial source material (e.g., cast iron) or melt pool fed carbon from a graphite crucible have reliably provided the necessary excess carbon to controllably keep the number of graphite layers small (3-5). For example, the phase diagram for $\mathrm{Ni}$ indicates that a $\mathrm{Ni}$ melt pool in contact with graphite should saturate to 18 at. $\%$ carbon at $2000{ }^{\circ} \mathrm{C}$. These two approaches were used most often in our experiments and explain the consistently smaller number of graphite layers present on our particles as compared to published pictures from various graphite arc processes (see Table I). Observations support the existence of both types of carbon sources. The qualitative observation of more layers on larger particles has been upheld by some experimental conditions. ${ }^{10,15}$ Other runs have displayed a near constant number of layers per particle across the $2-50 \mathrm{~nm}$ size range.

\section{SUMMARY AND CONCLUSION}

Dynamic inhomogeneities in the arc chamber set up a number of spatial pathways from evaporation to collection. Fluid flow seems to define multiple, physical pathways from evaporation to collection with different thermal histories, metal/carbon concentrations, and lengths. The local conditions on each pathway seem to activate a dominant mechanism among many simultaneously competing mechanisms that produce different nanoscale constituents. These constituents agglomerate within given pathways and as the pathways mix nearer to collection they form one of three types of collected products: (1) particle dominated agglomerates, (2) carbonaceous soot, or (3) a web. New mechanisms and modifications of previously proposed mechanisms account for all the nanoscale encapsulation morphologies observed in the tungsten arc method. Mechanisms from aerosol and catalysis literature are invoked to explain the particle size distribution and the construction of agglomerate and web products. Implications of the model also provide some insight into the observed variation in the number of graphite layers with particle size.

Numerous processing levers are available (arc current, electrode distance, pressure, jet speed, anode design, target composition, ... ) and each influences the final product through first and second order effects. They especially affect the crystallinity of the coatings and the amount of encapsulated versus other products produced. In particular we feel the role of catalytic materials and identification of the appropriate range of temperature and pressure to optimize the catalytic effect has been understated in the literature. In the model, however, only two dominant parameters are required to qualitatively capture the entire process-mechanism-product relationship. The two conceptual parameters are (1) the local path carbonto-metal ratio and (2) the global carbon-to-metal ratio. A simplified two-parameter processing-mechanism-product map summarizes the model in schematic form using one diagram for each parameter. The local carbon-tometal ratio dominates the first two stages of the model, specifying the formation of the nanoscale products as indicated in the first schematic. The global carbon-to- 
metal ratio dominates the third stage of the model that describes the interpathway balance that combines these nanoscale products to form the final collected product morphology.

This descriptive model linking processing parameters to possible mechanisms and final collected bulk products was developed for the tungsten-arc (W-arc) process during our experiments on $\mathrm{Fe}, \mathrm{Ni}$, and $\mathrm{Co}$ metals. Based primarily on the work of others, an attempt was made to extend the model for use in any gas phase aerosol arc process that forms nanometer particles in the presence of gaseous carbon (e.g., other elements, carboncarbon arc, future processes). A simple carbide versus metal core encapsulation rule was found for carbon containing arcs. If carbon is present in the arc (as opposed to introduction downstream), the local concentrations are assumed to determine the phase (metal or carbide) as per the phase diagram. However, processes that avoid the intimate and hot mixing of the metal and carbide may circumvent this restriction. It is hoped that introducing carbon downstream from the initial arc would allow encapsulation of carbide formers in their metallic state via a secondary process. This has not been tested. Alloys that suppress carbide formation, but contain the desired element, may prove useful as substitutes.

The model is still being refined and corrected as more data become available. Smaller details or specific mechanisms are likely to be better understood or replaced in the future. Under the guidance of this model, we have manipulated the fluid flow (physical pathways), global carbon-to-metal ratio, and other process controls available in the $\mathrm{W}$-arc system to greatly improve the quantity and quality of contiguously encapsulated transition metals, which was our original goal. We attribute this success to the selection of the appropriate local path carbon-to-metal ratio in more of the pathways. This model continues to guide our ideas for future process improvements and reactor designs.

\section{ACKNOWLEDGMENTS}

The authors would like to thank a number of people for their extensive support. D. Lynn Johnson was invaluable in process design and optimization. Julia R. Weertman provided extensive editorial comment and many scientific challenges. Her questions often drove us to new insights and new experiments. We also appreciate receiving a number of early preprints from Supapan Seraphin. Deb Serra, Mary Girard, and Mark Lowe aided in some of the experiments. Financial support for this work was provided by the Materials Research Center (MRC) of Northwestern University via DMR-9120521 and by the National Science Foundation (NSF) through DMR-9202574 and its NYI award program via DMR9357513.

\section{REFERENCES}

1. Y. Chai, T. Guo, C. M. Jin, R.E. Haufler, L.P.F. Chibante, J. Fure, L. H. Wang, J. M. Alford, and R.E. Smalley, J. Phys. Chem. 95, 7564-7568 (1991).

2. M. Tomita, Y. Saito, and T. Hayashi, Jpn. J. Appl. Phys. 32, Pt. 2, L280-L282 (1993).

3. S. Seraphin and D. Zhou, Appl. Phys. Lett 64, 2087 (1994).

4. R. T. K. Baker, Carbon 27, 315-323 (1989).

5. N. M. Rodriguez, J. Mater. Res. 8, 3233-3250 (1993).

6. S. Amelinckx, D. Bernaerts, X. B. Zhang, G. van Tendeloo, and J. Van Landuyt, Science 267, 1334-1338 (1995).

7. Y. Saito, M. Okuda, N. Fujimoto, T. Yoshikawa, M. Tomita, and T. Hatashi, Jpn. J. Appl. Phys. 33, Pt. 2, L526-L529 (1994).

8. S. Seraphin, J. Electrochem. Soc. 142, 290-297 (1995).

9. S. A. Majetich, J. H. Scott, E. M. Brunsman, and M. E. McHenry, in Science and Technology of Fullerene Materials, edited by P. Bernier, D. S. Bethune, L. Y. Chiang, T. W. Ebbesen, R. M. Metzger, and J. W. Mintmire (Mater. Res. Soc. Symp. Proc. 359, Pittsburgh, PA, 1995), pp. 29-34.

10. J. J. Host, M. H. Teng, B. R. Elliott, J-H. Hwang, T. O. Mason, J. R. Weertman, D. L. Johnson, and V.P. Dravid, J. Mater. Res. 12, 1268-1273 (1997).

11. V.P. Dravid, J. J. Host, M. H. Teng, B. R. Elliott, J-H. Hwang, D. L. Johnson, T. O. Mason, and J. R. Weertman, Nature 374, 602 (1995).

12. M. H. Teng, J. J. Host, J-H. Hwang, B. R. Elliott, J. R. Weertman, T. O. Mason, V.P. Dravid, and D. L. Johnson, J. Mater. Res. 10, 233-236 (1995).

13. Y. Saito, in Fullerenes: Recent Advances in the Chemistry and Physics of Fullerenes and Related Materials, edited by M. Kadish and R.S. Ruoff (The Electrochemical Society, Pennington, NJ, 1994), pp. 1419-1432.

14. V. P. Dravid, M. H. Teng, J. J. Host, B. R. Elliott, D. L. Johnson, T. O. Mason, J. R. Weertman, and J-H. Hwang, in United States Patent Office, Vol. 5472749 (Northwestern University, Evanston, IL, 1995).

15. D. Zhou, S. Wang, and S. Seraphin, in Proceedings 1994 Annual Meeting, Microscopy Society of America, New Orleans, LA, pp. $772-773$.

16. J-H. Hwang, V.P. Dravid, M.H. Teng, J. J. Host, B. R. Elliott, D. L. Johnson, and T. O. Mason, J. Mater. Res. 12, 1076-1082 (1997).

17. C. G. Granquist and R.A. Buhrman, J. Appl. Phys. 47, 2200 (1976).

18. R. C. Flagan and M. M. Lunden, Mater. Sci. Eng. A: Struct. Mater.: Prop. Microstruct. Process. A204, 113-124 (1995).

19. H. V. Nguyen and R.C. Flagan, Langmuir 7, 1807-1814 (1991).

20. T.E.W. Schumann and Q.J. Roy, Metero. Soc. 66, 195 (1940).

21. D. L. Swift and S. K. Friedlander, J. Colloid Sci. 19, 621 (1964).

22. D. Zhou, S. Seraphin, and J.C. Withers, Chem. Phys. Lett. 234, 233 (1995).

23. S. Seraphin, D. Zhou, and J. Jiao, unpublished.

24. S. Subramoney, R. S. Ruoff, D. C. Lorents, B. Chan, R. Malhotra, M. J. Dyer, and K. Parvin, Carbon 32, 507-513 (1994).

25. R. S. Ruoff, D. C. Lorents, B. Chan, R. Malhotra, and S. Subramoney, Science 259, 346-348 (1993).

26. M. Liu and J. M. Cowley, Carbon 33, 749-756 (1995).

27. S. Seraphin, D. Zhou, J. Jiao, J. C. Withers, and R. Loutfy, Nature 362, 503 (1993).

28. S. Seraphin, D. Zhou, J. Jiao, J. C. Withers, and R. Loutfy, Appl. Phys. Lett. 63, 2073 (1993).

29. S. Bandow and Y. Saito, Jpn. J. Appl. Phys. 32, Pt. 2, L1677-L1680 (1993). 
30. Y. Saito, T. Yoshikawa, M. Okuda, N. Fujimoto, S. Yamauro, K. Wakoh, K. Sumiyama, A. Kasuya, and Y. Nishina, J. Appl. Phys. 75, 134-137 (1994).

31. E. M. Brunsman, S. Anna, S. A. Majetich, and M.E. McHenry, in Science and Technology of Fullerene Materials, edited by P. Bernier, D. S. Bethune, L. Y. Chiang, T. W. Ebbesen, R. M. Metzger, and J. W. Mintmire (Mater. Res. Soc. Symp. Proc. 359, Pittsburgh, PA, 1995), pp. 35-40.

32. M. E. McHenry, S. A. Majetich, and E. M. Kirkpatrick, Mater. Sci. Eng. A A204, 19-24 (1995).

33. X. Lin, X. K. Wang, V.P. Dravid, R.P.H. Chang, and J.B. Ketterson, Appl. Phys. Lett. 64, 181-183 (1994).

34. Y. Wang, J. Am. Chem. Soc. 116, 397-398 (1994).

35. P. M. Ajayan, C. Colliex, J. M. Lambert, P. Bernier, L. Barbedette, M. Tence, and O. Stephan, Phys. Rev. Lett. 72, 1722-1725 (1994).

36. Y. Saito, T. Yoshikawa, S. Bandow, M. Tomita, and T. Hayashi, Phys. Rev. B 48, 1907 (1993).

37. S. Subramoney, P. V. Kavelaar, R. S. Ruoff, and D. C. Lorents, in Fullerenes: Recent Advances in the Chemistry and Physics of Fullerenes and Related Materials, edited by M. Kadish and R. S. Ruoff (The Electrochemical Society, Pennington, NJ, 1994), p. 1498.

38. R. D. Heidenreich, W. M. Hess, and L. L. Ban, J. Appl. Cryst. 1, 1-19 (1968).

39. O. Haase, R. Koch, M. Borbonus, and K. H. Rieder, in Proceedings of the 6th International Conference on Scanning Tunneling Microscopy-STM '91, Interlaken, Switzerland, 1991 (Ultramicroscopy), pp. $541-545$.

40. V. J. Kejrer and H. Leidheiser, J. Phys. Colloid. Chem. 58, 550 (1954).

41. T. Itoh and R. Sinclair, in Novel Forms of Carbon, edited by C. L. Renschler, J. J. Pouch, and D. M. Cox (Mater. Res. Soc. Symp. Proc. 270, Pittsburgh, PA, 1992), pp. 31-36.
42. R. T. K. Baker, M. A. Barber, P.S. Harris, F. S. Feates, and R. J. Waite, J. Catalysis 26, 51 (1972).

43. G. M. Jenkins and K. Kawamura, Polymeric Carbons (Cambridge University Press, 1976).

44. R. Terry, K. Baker, and N. M. Rodriguez, in Novel Forms of Carbon, edited by C. L. Renschler, J. J. Pouch, and D. M. Cox (Mater. Res. Soc. Symp. Proc. 270, Pittsburgh, PA, 1992), pp. 251-256.

45. M.M.R. Williams and S. K. Loyalka, Aerosol Science: Theory and Practice (Pergamon Press, Oxford, 1991).

46. N. A. Fuks, The Mechanics of Aerosols (Dover, New York, 1964).

47. M. Ata, Y. Kijima, H. Imoto, N. Matsuzawa, and N. Takahashi, Jpn. J. Appl. Phys., Part 1: Regular Papers \& Short Notes \& Review Papers 33, 4032-4038 (1994).

48. M. Ata, N. Matsuzawa, Y. Kijima, J. E. Seto, and H. Imoto, Jpn. J. Appl. Phys. Part 1: Regular Papers \& Short Notes \& Review Papers 32, 3549-3555 (1993).

49. D. Zhou, S. Wang, S. Seraphin, and J. C. Withers, in Novel Forms of Carbon, edited by C. L. Renschler, J. J. Pouch, and D. M. Cox (Mater. Res. Soc. Symp. Proc. 270, Pittsburgh, PA, 1992), pp. $337-342$.

50. D. Zhou, S. Seraphin, and S. Wang, in Novel Forms of Carbon II, edited by C.L. Renschler, D. M. Cox, J. J. Pouch, and Y. Achiba (Mater. Res. Soc. Symp. Proc. 349, Pittsburgh, PA, 1994), pp. 257-262.

51. D. S. Bethune, C. H. Klang, M. S. DeVries, G. Gorman, R. Savoy, J. Vazquez, and R. Beyers, Nature 363, 605-606 (1993).

52. S. A. Majetich, J. O. Artman, M. E. McHenry, N. T. Nuhfer, and S. W. Staley, Phys. Rev. B 48, 16845-16847 (1993).

53. R. S. Ruoff and S. Subramoney, Nature 366, 637 (1993). 